\title{
Desafios da educação de crianças que residem com suas mães em unidade prisional: o papel da Universidade e do poder público
}

Challenges of the education of children living with their mothers in prisions: the function of the University and public power

\section{Andrea Cristiane Maraschin Bruscato* Escola Infantil Interagir}

Ana Cristina Rangel** Centro Universitário Ritter dos Reis

Resumo O presente artigo apresenta o projeto de atenção ao desenvolvimento infantil dos bebês que residem com suas mães apenadas na instituição prisional, Penitenciária Feminina Estadual Madre Pelletier/RS. Ele promove ações visando ao bem-estar físico, afetivo e sócio cognitivo das crianças entre 3 e 12 meses, na perspectiva do cuidar e educar. Estudantes da Pedagogia, sob orientação e supervisão de professores do Curso, planejam e desenvolvem atividades educativas duas vezes por semana, considerando as especificidades da rotina carcerária e as necessidades de desenvolvimento dos bebês. Porém, é preciso reconhecer que faltam políticas públicas comprometidas com as necessidades de desenvolvimento dessas crianças para que possam assegurar que o vínculo mãe-bebê se estabeleça da forma mais saudável possível.

PAlaVRas-ChaVe: Creche; Educação; Presídio.

\begin{abstract}
This article presents the care project for infant development, considering babies who are living with their mothers at the penitential institution, Madre Pelletier Female Penitentiary, in Rio Grande do Sul State. The project promotes actions to secure the Physical well-being, affective and social cognitive among 3 to 12 months children, into the perspective of taking care of and educate them. Pedagogy students, under the professors' supervision and orientation in their courses, plan and develop educational activities twice a week, considering the particularities of prison's routine and the babies' development needs. However, it is necessary to recognize the lack of public policies responsible with the children development necessities in order to ensure that the connection between mother and child are established by the healthiest way.

KEYWORDS: Nursery; Education; Prison.
\end{abstract}


No Estado do Rio Grande do Sul, a população carcerária ultrapassa o número de vinte e nove mil pessoas, sendo 27.536 homens e 1.901 mulheres ${ }^{1}$. Apesar da diferença entre homens e mulheres parecer significativa, dados do Sistema Integrado de Informação Penitenciária (InfoPen) do Departamento Penitenciário Nacional (Depen) do Ministério da Justiça apontam que a entrada delas no crime vem aumentando gradativamente (SOARES \& ILGENFRITZ, 2002). Não é somente o aumento célere das mulheres nos cárceres que se torna fator preocupante, mas a quantidade de gestantes e, consequentemente, das crianças que residem nas penitenciárias, tornandose prioridade a implantação de políticas voltadas a esta temática real.

No Rio Grande do Sul, a rede prisional administrada pela Superintendência dos Serviços Penitenciários (Susepe) compreende unidades classificadas por fundação, albergues, penitenciárias, presídios, colônia penal e instituto penal. A Susepe, subordinada à Secretaria da Segurança Pública (SSP), é o órgão estadual responsável pela execução administrativa das penas privativas de liberdade e das medidas de segurança no Estado. De acordo com a Constituição do Rio Grande do Sul, a política penitenciária tem como objetivo a reeducação, a reintegração social e a socialização do preso, definindo como prioridades a regionalização e a municipalização dos estabelecimentos penitenciários, a manutenção de colônias penais agrícolas e industriais, a escolarização e profissionalização dos presos.

A mulher gestante, que se encontra na condição de presa no período gestacional e de amamentação, encontra-se em uma situação diferenciada e deve receber condições especiais de tratamento, garantido pela Constituição Federal de 1988, (Artigo 50-L -CF) e pela L.E.P. (Lei de Execução Penal V. Art. 89, Lei 7.210/84) de ficar com o seu bebê durante o período de aleitamento materno. Apesar de ser um direito, sua aplicabilidade vai depender se o estabelecimento prisional tiver estrutura para proporcionar uma permanência saudável, tanto para a mãe quanto para a criança. A vaga em estabelecimento que permita a internação pós-parto com local apropriado para receber a detenta e seu filho, não é direito assegurado para grande parcela de parturientes no sistema prisional, uma vez que, são poucas as unidades prisionais que contemplam esse tipo de acomodação com berçário apropriado. Na maioria das unidades prisionais, especialmente nas Cadeias Públicas, o berçário é uma cela improvisada, com as mesmas características de insalubridade comuns a esses locais, não sendo preparada para o abrigo de crianças.

Apesar de haver a possibilidade, em algumas unidades, do bebê permanecer por um período de amamentação de até seis meses ou mais, a separação entre mãe e filho ocorre inevitavelmente.

É notório que o aleitamento materno é fundamental para a nutrição da criança, e que o vínculo que o bebê estabelece com a mãe, no primeiro ano de vida, é estruturante no seu desenvolvimento. Entretanto, as estruturas carcerárias são, majoritariamente, improvisadas. A maioria das unidades foi construída para receber homens e, posteriormente, convertida em unidades prisionais femininas, não tendo espaço apropriado para a amamentação, berçário e creche para esses bebês, que nascem sob a custódia do Estado. 
No Rio Grande do Sul, as unidades do interior não permitem e não têm espaço para crianças, sendo as parturientes deslocadas para a Capital. As lactantes sofrem muito com o distanciamento dos outros filhos e preocupam-se com a situação econômica da família. Para usufruir ao direito de amamentar seu bebê por doze meses, é necessária a transferência para a Penitenciária Feminina Madre Pelletier (gestantes e presas com bebês até 6 meses), ou Guaíba (presas com bebês de seis a doze meses). $\mathrm{O}$ acolhimento dessa mãe apenada e bebê têm como objetivo garantir o aleitamento materno e cuidados apropriados, como acompanhamento psicológico e pediátricos.

Foi atento a essa realidade que se iniciou o Projeto de Atenção em Educação Infantil na Unidade Prisional Madre Pelletier, buscando minimizar os efeitos do cárcere nas crianças pequenas, filhas de apenadas, que "moraram" com suas mães na prisão. Apesar da inserção dessas crianças em ambiente prisional ser algo polêmico, é a única forma de contribuir para o vínculo materno e evitar o abandono e a separação da mãe nessa etapa fundamental que é a infância.

É fato que o contato da mãe com o filho nos primeiros anos de vida é necessário em razão da previsibilidade que o bebê constrói a partir do conhecimento maternal. Segundo Winnicott (1982, p. 205), o papel da mãe é apresentar o mundo ao bebê e provê-lo de um ego auxiliar que lhe permita integrar suas sensações corporais aos estímulos ambientais e suas capacidades motoras nascentes. Os modos de perceber, representar e atuar sobre o meio, os sentimentos em relação ao mundo, ao outro e a si mesmo, que iniciarão através do vínculo mãe-bebê, irão, mais tarde, formar a base para as futuras relações sociais desta criança.

A vida encarcerada dos pequenos tem suas limitações, tanto pelas condições físicas quanto pelas sociais. Por não terem a efetiva visibilidade, apesar de consideradas legalmente como pessoas em desenvolvimento, essas crianças estão relegadas ao "fechamento social", com horários e dias para visitar familiares, tomar sol, etc. Para minimizar os efeitos das relações entre criança-mãe (que sofre as consequências de uma transgressão social), foi construído, nessa penitenciária, o espaço da Brinquedoteca, para a realização de ações educativas que oportunizassem melhores condições ao desenvolvimento dos bebês.

A reforma da lavanderia para reutilização do espaço e transformação em Brinquedoteca iniciou no ano de 2007, e contou com a ajuda da comunidade para doações de brinquedos e outros objetos, garantindo um espaço saudável e seguro às crianças residentes nessa instituição penal.

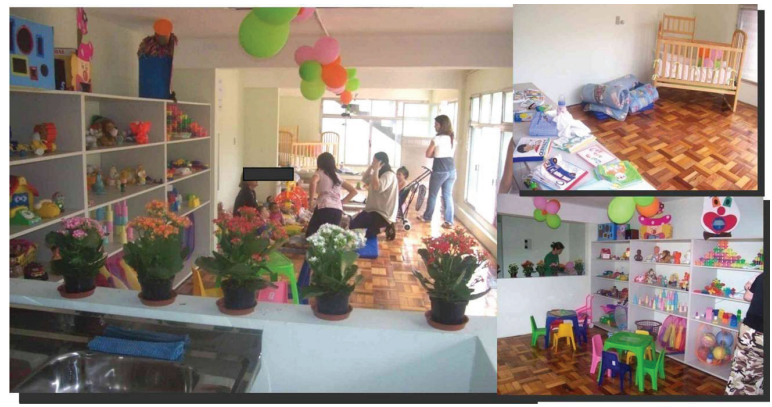

Figura 1: espaço interno da Brinquedoteca inaugurada em 2008. 


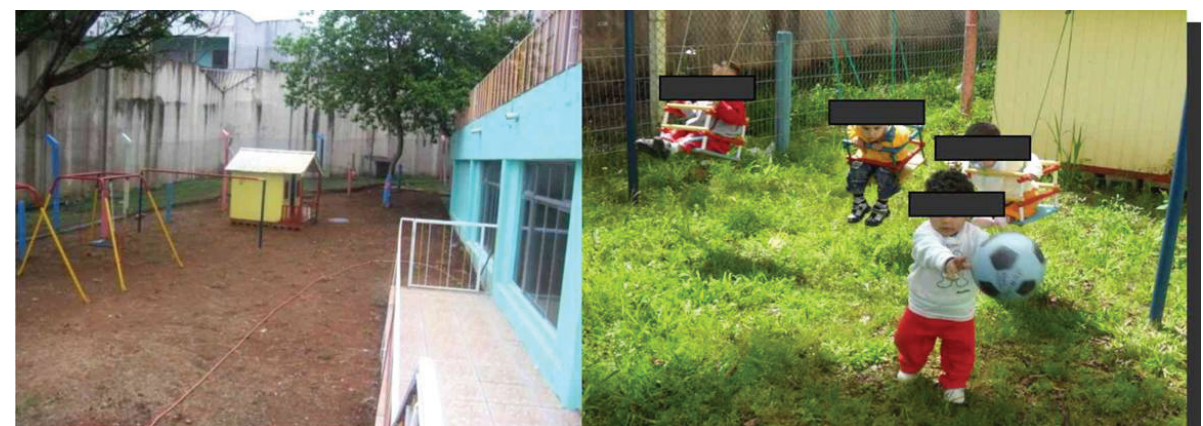

Figura 2: espaço externo para brincar e tomar sol, com brinquedos doados por uma creche da comunidade.

Um dos princípios assumidos na organização da ação educativa foi o valor atribuído ao novo ambiente como parceiro pedagógico do educador, além da intencionalidade da intervenção do adulto favorecendo a interação da criança com outras crianças, com os diferentes recursos, brinquedos e espaços, para descobrir propriedades dos objetos, suas possibilidades de agir, movimentar, criar, expressar, negociar, brincar, estabelecer relações e ser feliz. Também se investiu na relação mãe-bebê, em atividades diversas que tinham como intencionalidade criar um ambiente mais favorável às interações entre as mães e seus bebês. A exemplo dessas atividades, por ocasião das datas comemorativas, se promoveram encontros diversos, como práticas da massagem Shantala ${ }^{2}$ em que as mães foram instruídas em técnicas de interação com seus filhos. Esses encontros aconteceram no espaço da brinquedoteca.

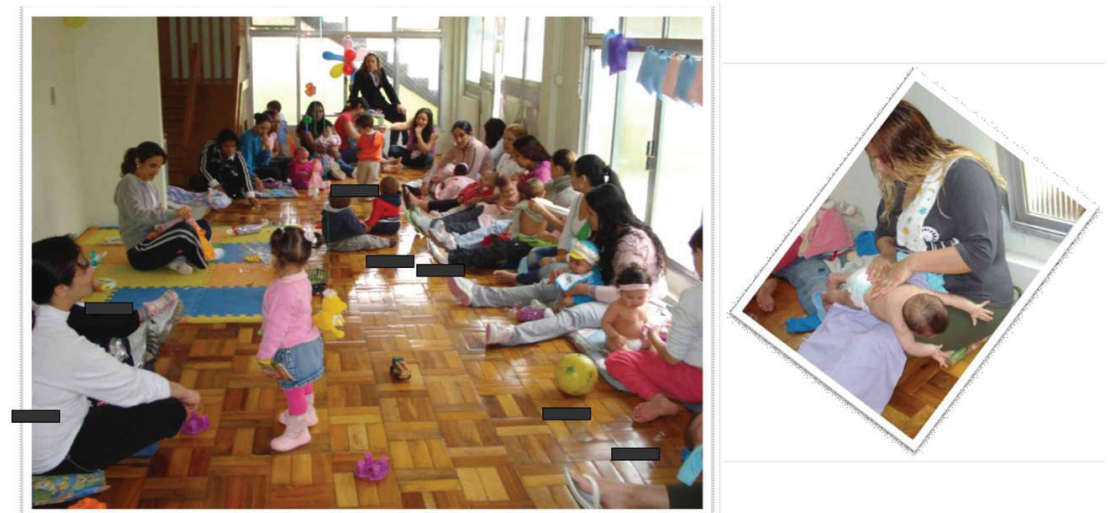

Figura 2: espaço externo para brincar e tomar sol, com brinquedos doados por uma creche da comunidade.

A Shantala traduz um momento especial oferecendo a oportunidade da mãe ter um contato mais prolongado com o bebê. $\mathrm{O}$ toque carinhoso é a melhor forma de se aproximar da criança, transmitindo amor e carinho através das mãos. Esse contato ajudará os pais a conhecerem o corpo do seu filho e se comunicar com ele. (GURGEL, 2009, 1).

É sabido que o bebê-humano é o único animal que precisa de cuidados para sobreviver. Ao nascer, ele tem o corpo extremamente frágil, razão pela qual precisa de cuidados parentais. A mãe (ou cuidador) inaugurará o veículo de toda e qualquer inscrição psíquica: o laço social. É a mãe que interpretará as primeiras necessidades dessa 
criança, em uma interlocução que possibilitará ao bebê suas primeiras inscrições simbólico-imaginárias, para que, um dia, possa saber que está com frio, fome, dor, medo. Isso é o que há de mais fundamental em uma criança e que dará sustentação a outras aquisições, permitindo construir laços pertencentes a uma história (DOLTO, 1996).

Para Kurowsky (1990), o primeiro e mais persistente de todos os vínculos é aquele entre mãe e filho pequeno, que frequentemente persiste até a idade adulta. A característica essencial da vinculação afetiva é que os dois parceiros (mãe e filho) tendem a manter-se próximos um do outro, e qualquer tentativa, por parte de terceiros, para separá-los, encontrará vigorosa resistência. $\mathrm{O}$ autor defende que o convívio mãefilho no período inicial da vida do bebê é de fundamental necessidade:

É comprovadamente produtivo considerar muitos distúrbios psiconeuróticos e da personalidade nos seres humanos com um reflexo de um distúrbio na capacidade para estabelecer vínculos afetivos, em virtude de uma falha no desenvolvimento na infância ou de um transtorno subsequente. (KUROWSKY, 1990, p. 15).

Spitz também afirma que a relação mãe-bebê traz inúmeros benefícios à criança:

\begin{abstract}
O amor e a afeição pelo filho o tornam um objeto de contínuo interesse para a mãe; e além desse interesse persistente ela lhe oferece uma gama sempre renovada, rica e variada, todo um mundo, de experiências vitais. O que torna essas experiências tão importantes para a criança é o fato de que elas são interligadas, enriquecidas e caracterizadas pelo afeto materno; e a criança responde afetivamente a esse afeto. Isto é essencial na infância, pois neste idade os afetos são de importância muitíssimo maior do que em qualquer outro período posterior da vida no decorrer de seus primeiros meses, a percepção afetiva e os afetos predominam na experiência do bebê, praticamente com exclusão de todos os outros modos de percepção. (SPITZ, 1998, p. 99).
\end{abstract}

Assim, garantir o vínculo mãe-bebê durante a fase inicial de vida é fundamental. A Constituição Federal, por exemplo, dispõe que às presidiárias serão asseguradas condições para que possam permanecer com seus filhos durante o período de amamentação (art. $5^{\circ}$, inc. L), enquanto o Estatuto da Criança e do Adolescente - Lei 8.069/1990 - estabelece que o Poder Público, as instituições e os empregadores propiciarão condições adequadas ao aleitamento materno, inclusive aos filhos de mães submetidas à medida privativa de liberdade (art. $\left.9^{\circ}\right)$. A Lei de Execução Penal do RS - Lei 7210/84 - também determina que os estabelecimentos penais destinados a mulheres serão dotados de berçário, onde as condenadas possam amamentar seus filhos (art. 82, § $2^{\circ}$ ), prevendo ainda que a penitenciária de mulheres poderá ser dotada de seção para gestante e parturiente e de creche com a finalidade de assistir ao menor desamparado cuja responsável esteja presa (art. 89). Logo, cabe ao Ministério Público fiscalizar o cumprimento das leis, promovendo, se o caso, medidas judiciais de forma a cumpri-lo. 
Santa Rita ${ }^{3}$ (2009) chama a atenção para o período ou idade máxima de permanência da criança junto à mãe que cumpre pena de prisão, havendo uma variação de 04 meses a 06 anos, o que comprova a falta de uma legislação específica para o caso. Segundo a autora, a própria Constituição Federal e a Lei de Execução Penal não definem um período de tempo mínimo; apenas mencionam o direito que as presas têm de amamentar os seus filhos ou filhas.

O artigo de Armelin; Mello e Gauer (s.d), intitulado Filhos do Cárcere: Estudo sobre as mães que vivem com seus filhos em regime fechado ${ }^{4}$, alerta para o fato que poucas instituições penais brasileiras possuem locais destinados ao cuidado e ao desenvolvimento saudável da criança que está alojada junto à sua mãe apenada. Tal dado é preocupante, se levarmos em conta: 1) a importância dos vínculos primários que se constituem entre mães e filhos; 2) a não-garantia de um direito constitucional ser cumprido; 3) a falha do Poder Público, seja em garantir o número de vagas em instituições prisionais, seja em fiscalizar estes estabelecimentos; 4) a negligência aos direitos das crianças, garantidos através do Estatuto da Criança e do Adolescente; 5) outros.

Pesquisas indicam que, durante os primeiros anos de vida, 90\% das conexões cerebrais dos bebês são definidas através da interação deste com estímulos do meio (MEC, 2004), e que os estímulos como sons, formas, cores, texturas, etc ajudam a configurar uma "arquitetura cerebral mais potente, com mais ligações entre os neurônios-sinapses" (BATISTA, 2007, p. 171). Logo, os adultos que interagem com recémnascidos são importantes para sua sobrevivência, mas também para a sua aquisição de diversas habilidades (motoras, perceptivas, cognitivas, linguísticas e sociais). Deste modo, é grande a responsabilidade do adulto que interage com crianças de berçário em dar continuidade ao que o bebê já vinha construindo em sua história familiar, e se dispondo a ser mais um a descobrir suas singularidades: como se alimenta, como se acalma, dorme, brinca, além de estimulá-lo com uso das diversas linguagens.

O ser humano é bastante sensível aos estímulos do meio durante o período da primeira infância, quando ocorrem as mudanças de crescimento mais significativas. Deste modo, os desafios dos profissionais da Educação Infantil são inúmeros, devendo estar atentos aos referenciais teóricos e práticos que sustentarão a ação pedagógica.

A influência ativa do professor é determinante para a expansão do campo mental e das funções cognitivas que resultarão devido aos estímulos propostos por ele e pelo meio. As ações devem favorecer experiências de sua cultura, das linguagens que essa cultura produziu e produz para interpretar, configurar e compartilhar sensações. Se a criança vem ao mundo e se desenvolve em interação com a realidade social e cultural, é possível pensar uma proposta educacional que lhe permita explorar esse mundo através da vivência em experiências diversificadas, que lhe possibilitam a manifestação do potencial físico, afetivo e intelectual, a aprendizagem de sua autonomia e de sua socialização, além da integração social (KUHLMANN JR, 1999).

De que jeito deve ser vivida a infância das crianças em instituiçôes prisionais? Há diferença entre a creche do presídio e outras? O trabalho no presídio compóe um tipo de instituição escolar ou não? Educar e cuidar, como e para quê?? Como se caracterizam as instituições de educação infantil? 
A intencionalidade do trabalho educativo proposto pelos alunos do curso de Pedagogia, com orientação e supervisão de professores, visa maximizar o desenvolvimento dos pequenos através da manipulação, transformação e combinação de materiais variados, proporcionando aprendizagens através do contato com diferentes linguagens (musical, literária, corporal, espacial, plástica, etc). Eles estudam e discutem questões pontuais sobre currículo e primeira infância: $O$ que se espera de uma ação pedagógica para bebês dento da unidade prisional? Existe um currículo para crianças bem pequenas? Qual é a intencionalidade do trabalho pedagógico? A partir dessas e outras questões que vão emergindo, o grupo organiza-se para o estudo, lista as características da faixa etária e discute a pluralidade dos espaços educativos, revendo os conceitos sobre escola, infância e currículo. Trata-se de um desafio à educação de zero a um ano, que configura "currículo" como as experiências nas diferentes linguagens. Os alunos participantes do projeto têm a responsabilidade de estarem presentes, observando e procurando dar sentido às múltiplas linguagens, respondendo adequadamente aos desejos, gostos e aflições das crianças; devem estar atentos e sensíveis ao modo de como os bebês sentem, percebem e agem no mundo, estimulando-os através da música, sombras, cores, etc.

Segundo Barbosa e Richter (2009), os bebês sabem muitas coisas que culturalmente os adultos não conseguem ver e compreender. As suas formas de interpretar, significar e comunicar emergem do corpo e acontecem através de movimentos expressivos e comunicativos anteriores à linguagem verbal e que constituem, simultâneos à criação do campo da confiança, os primeiros canais de interação com o mundo e os outros. Para realizar algo ou conseguir o que desejam, por exemplo, as crianças lançam mão de uma série de ações, que vão desde engatinhar, balbucios, choros, sorrisos a outros movimentos. Essas ações começam como atos involuntários ou reflexos, até se transformarem em feitos intencionados para chegar ao resultado esperado: seja mamar, ganhar colo ou trocar a fralda. Logo, interações com os pequenos de forma a estimulálos em sua aprendizagem torna-se fundamental, ainda mais em uma instituição penal.

Os preceitos da Lei de Diretrizes e Bases da Educação - N. 9.394/96, LDB, estabelece que a educação infantil é a primeira etapa da educação básica e tem como finalidade o desenvolvimento integral da criança até os cinco anos de idade, em seus aspectos físico, intelectual e social, complementando a ação da família e da comunidade (art. 29). Ela prevê a integração de creches e pré-escolas aos sistemas de ensino, atuando com quadro de educadores providos de profissionalização específica. Ou seja, existe uma lei nacional que afirma a importância do atendimento especializado para crianças de zero a cinco anos, de forma a garantir, por meio de diferentes linguagens, seu desenvolvimento através das interações que estabelecem com as outras pessoas e com o meio em que vivem.

A Lei Estadual do RS n.12.544, de 03 de julho de 2006, que instituiu o programa Primeira Infância Melhor (PIM), de ação sócio-educativa voltado às famílias com crianças de zero até seis anos e gestantes que se encontram em situação de vulnerabilidade social, também deveria assegurar um atendimento específico aos bebês, que encontram-se "encarcerados" junto às suas mães. Mas parece que, em uma conjuntura marcada por agravantes processos de desigualdade e exclusão social, a polí- 
tica brasileira de educação infantil ainda está calcando os patamares de efetividade no campo das políticas públicas, as quais já se podem inferir, de imediato, as complicações de inserção desta na esfera da política penitenciária.

Diante de uma análise mais crítica sobre os dados penitenciários, pode-se considerar que a situação do atendimento infantil aos filhos de mulheres encarceradas, além de ser assunto polêmico, parece não dialogar com o campo dos direitos da política para a infância. É como se disséssemos que as leis existem, mas o cumprimento delas e a garantia às mães e bebês ainda estão longe de concretizar-se.

A construção da dignidade é um processo tanto mais complexo e longo quanto maiores as desigualdades sociais e os preconceitos e discriminações enraizadas no cotidiano da sociedade. Mudanças socioculturais exigem a consciência de sua necessidade, a disposição para luta e o conhecimento da causa dos problemas e, entre outras coisas, o próprio conhecimento de quais são os problemas a serem equacionados. (OLIVEIRA, 2003, p. 82).

Outra preocupação do projeto tem sido colaborar para a construção de um ambiente mais propício à qualidade de vida e das relações entre as presas da ala materno-infantil, seja através de encontros reflexivos sobre o papel da mulher na sociedade, a importância da maternidade, vínculos afetivos e/ou atividades de integração.

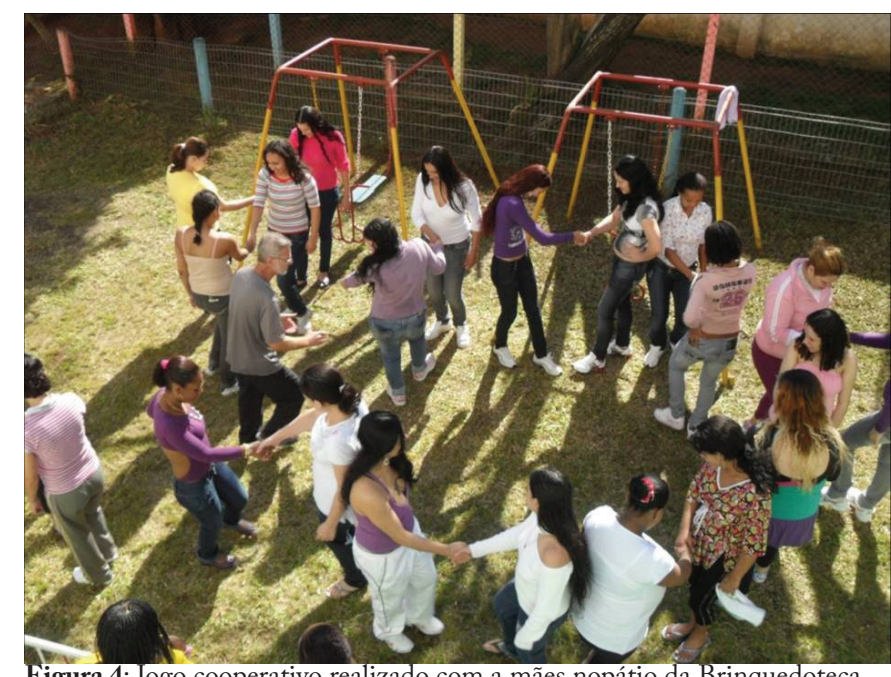

Figura 4: Jogo cooperativo realizado com a mães nopátio da Brinquedoteca.

\section{Segundo Kurowsky,}

$\mathrm{O}$ aprisionamento causa na interna uma ansiedade muito grande, um sentimento de inferioridade, impotência, menos valia, e tendo a presa a oportunidade de estar junto com seu filho, poderá aliviar essa situação, dedicando boa parte de seu dia em função do filho, e/ ou um trabalho que estará diretamente ligada a ele, onde ela canalizará sua energia. (KUROWSKY, 1990, p. 34). 
Ao longo do período de implantação e execução do projeto na penitenciária Feminina Madre Pelletier, tem-se constatado alto grau de satisfação dos envolvidos nesse trabalho, seja por meio de análise dos depoimentos, da documentação através de fotos ou reflexão sobre os resultados relacionando teoria-prática, fato que incentiva sua viabilidade a partir das condições e de alguns impactos que foram observados, tais como:

1) a construção de um espaço qualificado para as interações das crianças, favorecedor do desenvolvimento infantil, contemplando diferentes áreas como: higiene, jogo, brinquedo, literatura e a livre movimentação no espaço interno e externo (pátio);

2) a evolução das crianças que frequentavam o espaço e participavam das atividades intencionalmente organizadas para favorecer o desenvolvimento infantil;

3) a valorização da maternidade e da relação mãe-bebê, pelo acompanhamento das mães ao trabalho realizado e sua participação nas oficinas e atividades promovidas pelo projeto;

4) a aprendizagem realizada pelos alunos monitores, não somente nas questões pedagógicas, mas, principalmente no enfoque social;

5) a oportunidade de a Universidade refletir sobre temáticas envolvidas no trabalho por meio de artigos escritos e da apresentação do projeto em Salões de Extensão que contribuem para chamar a atenção da sociedade à realidade dessas crianças, até então "invisíveis", colaborando para a discussão da necessidade de criação de políticas públicas mais favoráveis à qualidade de vida dos bebês, incluindo o cuidado na relação com suas mães;

6) o cumprimento dos princípios de responsabilidade social e desenvolvimento humano sustentável, numa experiência extensionista que também evidencia o princípio da indissociabilidade entre as atividades de pesquisa, o ensino e extensão.

Esses pontos observados levam ao compromisso cada vez maior em organizar ações educativas no atendimento às crianças, filhos e filhas de detentas, permeadas pela complexidade do debate que, muitas vezes, obriga a ressignificar posicionamentos frente à complexidade da realidade da educação em unidades prisionais.

À medida que a Universidade propicia a inserção de alunos e professores na realidade de uma comunidade frágil, contribui com a humanização da vida prisional de mães e filhos e forma cidadãos éticos, comprometidos com a transformação da realidade social.

As políticas públicas devem convergir para oferecer às crianças, moradoras de presídios e penitenciárias, as mesmas condições de direito e acesso às creches públicas, possibilitando relações educativas travadas no espaço de convívio coletivo. Não basta a legislação brasileira atestar que as presas podem ficar com os bebês durante a amamentação, ou a Lei de Execução Penal determinar berçários na prisão. É preciso valer os direitos das crianças de: 1) estarem junto às mães durante os primeiros anos de vida; 2) frequentarem uma instituição de educação infantil fora dos muros do presídio, 
como todas as crianças. Se o Estatuto da Criança e do Adolescente garante direitos iguais para todas as crianças, não há como diferenciá-las por estarem confinadas em instituições carcerárias.

Há muito o quê fazer e oportunizar para que esses bebês tornem-se "visíveis" à sociedade, com garantias iguais, principalmente no campo educacional. A transformação pretendida necessita de projetos que deverão ser construídos em redes, articulando a Universidade, a comunidade e o poder público: esse é um desafio ainda a ser conquistado na realidade brasileira.

\section{Referências}

ARMELIN, B; MELLO, D; GAUER, G. Filhos do cárcere: estudo sobre as mães que vivem com seus filhos em regime fechado. Disponível em: <http://revistaseletronicas.pucrs.br/ojs/index.php/graduacao/article/viewFile/7901/5586>. Acesso em: 22 mar. 2013.

BARBOSA, M. C. S.; RICHTER, S. R. S. Qual currículo para bebês e crianças bem pequenas? In: BRASIL, MEC. Salto para o futuro. Educação de crianças em creches. Brasília, outubro 2009. Ano XIX, n. 15, p. 25.

BATISTA, C. V. M. Entre Fraldas, Risos e Choros: por uma prática educativa com bebês. In: PASCHOAL, J. D. (coord.); MORENO, G. L.; AQUINO, O. R.; Trabalho pedagógico na educação infantil. Londrina: Edições Humanidades, 2007.

BRASIL. Constituição (1988). Constituição da República Federativa do Brasil. 25. ed. São Paulo: Saraiva, 2000.

. Estatuto da criança e do adolescente - Lei 8.069/1990. Brasília, 1990. Disponível em: <http://www.planalto.gov.br/ccivil_03/Leis/L8069.htm> Acesso em: 12 dez. 2004

BRASIL. Lei de Execução Penal - Lei no ${ }^{\circ}$ 7.210/84. Disponível em: <http://www.planalto.gov. br/ccivil_03/LEIS/L7210.htm> Acesso em: 24 abr. 2015.

BRASIL. Lei n. 9.394/96, de 20 de dezembro 1996. Estabelece as diretrizes e bases da educação nacional. Diário Oficial da União, Brasília: 23 dez. 1996. p. 27894.

BRASIL, MEC. Saberes e práticas da inclusão. Educação infantil. Dificuldades acentuadas de aprendizagem ou limitações no processo de desenvolvimento. Brasília, 2004.

BRASIL. Ministério da Justiça. Departamento Penitenciário Nacional. Mulheres Encarceradas - Diagnóstico Nacional. Consolidação dos Dados Fornecidos pelas Unidades da Federação, 2008.

DOLTO, F. Quando surge a criança. São Paulo: Papirus, 1996.

GURGEL, D. Shantala. Disponível em: <http://www.cursoshantala.com.br/shantala.htm.> Acesso em: 21 mar. 2013.

KUHLMANN JR., M. Educação infantil e currículo. In: FARIA, A. L. G.; PALHARES, M. S. (Orgs.). Educação infantil pós-LDB: rumos e desafios. Campinas: Autores Associados, 1999.

KUROWSKI, C. M. Análise crítica quanto a aspectos de implantação e funcionamento de uma creche em penitenciária feminina. Porto Alegre, $1990.37 \mathrm{f}$.

OLIVEIRA, G. Dignidade e direitos humanos. Curitiba: UFPR, 2003.

RIO GRANDE DO SUL. Ministério Público. Lei Estadual No 12.544, de 03 de Julho De 2006. Institui o Programa Primeira Infância Melhor - PIM. Disponível em: <http://www.mprs. mp.br/infancia/legislacao/id3192.htm> Acesso em: 24 abr. 2015. 
Desafios da educação de crianças que residem com suas mães em unidade prisional: o papel da Universidade e do poder público

SANTA RITA, R. Criança em ambiente penitenciário: uma análise da experiência brasileira. Revista VoxJuris, ano 2, v. 2, n. 1, p. 203-220, 2009.

SOARES, B. M.; ILGENFRITZ, I. Prisioneiras - vida e violência atrás das grades. Rio de Janeiro: Garamond, 2002.

SPITZ, R. A. O primeiro ano de vida: um estudo psicanalítico do desenvolvimento normal e anômalo das relações objetais. 2. ed. São Paulo: Martins Fontes, 1998. 390 p.

WINNICOTT, D.W. A criança e o mundo. Rio de Janeiro: LTC, 1982.

\section{Notas}

${ }^{1}$ Fonte: Departamento de Segurança e Execução Penal - Susepe - Atualizado em 09/01/2013. In: http:// www.susepe.rs.gov.br/capa.php > Acesso em: 14 jan. 2013.

${ }^{2}$ A Shantala é uma massagem milenar indiana. Foi apresentada ao ocidente pelo médico francês Frédérick Leboyer que, de passagem pela Índia, se deparou com a cena de uma mulher num calçada pública massageando seu bebê. Graças à "descoberta" de Leboyer, e ao seu livro: SHANTALA, massagem para bebês: uma arte tradicional, a técnica tornou-se popular.

${ }^{3} \mathrm{O}$ trabalho de Rosângela Santa Rita refere-se à análise de uma situação particular vivenciada por mulheres presas, com filhos, no espaço de execução penal. Trata-se de demonstrar a existência de complexidades relativas à institucionalização da mãe presa, ainda sem visibilidade na agenda pública brasileira.

${ }^{4} \mathrm{O}$ artigo Filhos do cárcere: estudo sobre as mães que vivem com seus filhos em regime fechado, de ARMELIN, B; MELLO, D; GAUER, aluna, pesquisadora e orientador da PUCRS, respectivamente, está disponível em: http://revistaseletronicas.pucrs.br/ojs/index.php/graduacao/article/viewFile/7901/5586. Acesso em: 22 mar. 2013. Foi publicado sem data (s.d).

* Doutoranda em Educação pela Universidade Federal do Rio Grande do Sul, Porto Alegre, Rio Grande do Sul, Brasil.

** Professora do Centro Universitário Ritter dos Reis (UniRitter), Porto Alegre, Rio Grande do Sul, Brasil.

\section{Correspondência}

Andrea Cristiane Maraschin Bruscato - Escola Infantil Interagir. Rua Dr. Pereira Neto, 84, Tristeza, CEP: 91920-530 - Porto Alegre, Rio Grande do Sul, Brasil.

E-mail: bruscato@terra.com.br - ana_rangel@uniritter.edu.br

Recebido em 07 de março de 2014

Aprovado em 16 de maio de 2014 